\title{
PENGEMBANGAN LABORATORIUM VIRTUAL PADA MATERI LAJU REAKSI UNTUK KIMIA DASAR II PRODI PENDIDIKAN KIMIA
}

\author{
Epinur ${ }^{1}$, Yusnidar \\ Fakultas Keguruan dan Ilmu Pendidikan, Universitas Jambi \\ 1email: epinur54@gmail.com
}

\begin{abstract}
Reaction rate learning requires experiments or practicum identical to the laboratory, so the implementation of the lab is highly dependent on the existence and completeness of the laboratory. Chemical concepts based on experiments, one of which is the concept of reaction rate consisting of the concept of reaction rate, factors influencing rate and reaction order. With the advancement of technology in the field of ICT, there are many programs that can be utilized to design lab work based on ICT (virtual lab). Virtual labs can resolves the limitations of laboratories, tools and materials, time and cost savings. This development research aims to find out the process of developing a virtual laboratory on reaction rate material using Adobe Flash6 Professional program until it is declared eligible to be used for Basic Chemistry II course in chemical education program. This type of research is development research. The product developed in the form of virtual laboratory using Adobe Flash6 Professional program on reaction rate material for Chemistry II course in chemistry education program. The study of virtual laboratory development on this reaction rate material using the ADDIE model. Based on material and media validation, the resulting virtual lab is feasible and heavily used in learning.
\end{abstract}

\section{Keywords: Virtual lab, Adobe Flash CS6 Professional, Reaction rate}

\section{PENDAHULUAN}

Materi laju reaksi adalah salah satu materi dari mata kuliah Kimia Dasar II yang mempelajari konsep laju reaksi, faktor-faktor yang mempengaruhi laju reaksi dan penentuan orde reaksi. Dalam tujuan pembelajarannya dikatakan bahwa penguasaan konsep oleh mahasiswa adalah melalui percobaan/praktikum, sama halnya dengan materi asam-basa dan materi-materi kimia lainynya. Senada dengan itu Bradley, et al. dalam Sutrisno (2011) mengatakan bahwa pembelajaran bidang studi kimia merupakan rumpun sains, dalam pelaksanaannya dilapangan diharapkan berdasarkan pada percobaan baik langsung maupun secara virtual.

Untuk merealisasikan tuntutan tujuan pembelajaran laju reaksi tersebut, maka pada mata kuliah Praktikum Kimia Dasar dimasukan topik praktikum faktor-faktor yang mempengaruhi laju reaksi dan penentuan orde reaksi. Mata kuliah Kimia Dasar II dan mata kuliah Praktikum Kimia Dasar ditawarkan pada semester yang sama. Mata kuliah praktikum dilaksanakan di laboratorium, sedangkan mata kuliah Kimia Dasar II di ruang kuliah Akibatnya pelaksanaan praktium tidak sejalan dengan teori, terkadang praktikum dilaksanakan setelah materi dipelajari. Disisi lain pelaksanaan praktikum sering mengalami kendala dengan keterbatasan alat dan bahan. Bradley, et al. dalam (Sutrisno, 2011) mengungkap beberapa persoalan mengenai kendala penyelenggaraan percobaan secara langsung, yaitu: tidak tersedia peralatan dan bahan kimia yang memadai, tidak adanya laboratorium, tidak adanya asisten laboratorium, percobaan dianggap sebagai sesuatu yang membahayakan sehingga dalam pelaksanaannya dibutuhkan persiapan dan pengalaman di laboratorium. Padahal menurut Donlley, et al. (Sutrisno, 2011) dengan melakukan percobaan akan memberikan pemahaman kepada mahasiswa dalam ilmu kimia ke arah yang realitas dan menarik, 
memahami konsep-konsep yang bersifat abstrak menjadi lebih mudah dipahami. Selain itu, dengan melakukan percobaan mahasiswa dapat melakukan ilustrasi metode ilmiah yang dapat mengembangkan "practical skill".

Dalam rangka mewujudkan "practical skill" yang diharapkan, oleh Sutrisno (2011) diungkapkan peran TIK sebagai alat bantu dalam pembelajaran khususnya untuk mengembangkan kreativitas dosen kimia, inovasi dalam pembelajaran, mendorong minat mahasiswa untuk tertarik dengan ilmu kimia, dan membawa konsep-konsep yang abstrak ke dunia lebih nyata agar lebih komunikatif dan inovatif dalam proses pembelajarannya. Berbagai perangkat komputer beserta koneksinya dapat menghantarkan peserta belajar secara cepat dan akurat apabila dimanfaatkan secara benar dan tepat. Untuk itu dibutuhkan sumber daya manusia yang tanggap terhadap perkembangan TIK. Selain itu, juga diungkapkan oleh Sutrisno (2012) bahwa integrasi TIK dalam pembelajaran dapat menciptakan iklim belajar yang efektif bagi mahasiswa yang lambat, tetapi juga dapat memacu efektivitas belajar bagi mahasiswa yang lebih cepat. Hal ini dibuktikan dengan tersedianya berbagai media pembelajaran yang didasarkan pada pandangan konstruksi pengetahuan. Sehingga peran media pembelajaran tersebut sebagai alat bantu kognitif tidak hanya efektif, efisien, dan praktis dalam menunjang kegiatan pembelajaran di kelas, namun juga sebagai sumber belajar mandiri bagi mahasiswa. Salah satu media pembelajaran yang dimaksud tersebut adalah laboratorium virtual.

Peran laboratorium virtual diungkapkan oleh Asyhar (2012), yaitu: dapat meningkatkan motivasi mahasiswa dalam belajar, bersifat praktis untuk digunakan, efisien, tidak berbahaya, dapat meminimalisir kesalahan penafsiran, menunjang pemahaman mahasiswa, serta laboratorium virtual juga dapat memberikan ilustrasi mikroskopis. Epinur dan Yusnidar (2016) telah mengembangkan Laboratorium Virtual Dengan Macromedia Flash 8 Materi Larutan Asam-Basa Untuk Kimia Dasar II Prodi Pendidikan Kimia dan diperoleh hasil produk yang dikembangkan layak digunakan dan disukai oleh mahasiswa. Beberapa penelitian lainnya yang mengungkapkan peran penggunaan media laboratorium virtual, yaitu penelitian yang berjudul "Effect of a Virtual Chemistry Laboratory on Students' Achievement", dilakukan oleh Tatli dan Ayas (2013); "Pengaruh Penerapan Praktikum Virtual Berbasis Problem Solving Terhadap Kemampuan Berpikir Kritis Mahasiswa" oleh Sutarno (2013); "Hubungan Motivasi dengan Kerja Ilmiah Siswa dalam Pembelajaran Fisika Menggunakan Virtual Laboratory di Kelas X SMAN Kota Padang" oleh Razi. (2013); "Pengaruh Model Pembelajaran (Berbantuan Laboratorium Virtual) dan Minat Belajar Terhadap Kemampuan Berpikir Kreatif Kimia" oleh Pujiati, A. dan Nurhayati (2014); serta Yang dalam Pujiati. dan Nurhayati (2014) mengungkapkan hasil studi di East California University bahwa laboratorium virtual membantu mahasiswa memahami konsep dan teori, serta sangat potensial untuk meningkatkan efektivitas pembelajaran secara signifikan.

Pada penerapannya, pengembangan laboratorium virtual tidak lepas dari peran suatu perangkat lunak yang menjadi alat untuk merancang dan mengembangkan laboratorium tersebut. Salah satu program yang dapat digunakan untuk merancang dan mengembangkan laboratorium virtual adalah program Adobe Flash CS6 Profesional. Perangkat lunak ini telah digunakan secara luas untuk membangun berbagai jenis media pembelajaran. Program Adobe Flash menjadi alternatif yang dipilih untuk mengembangkan laboratorium virtual didasarkan pada beberapa alasan, diantaranya program ini dapat dengan mudah di install diberbagai jenis windows, mudah diperoleh dengan mengunduh secara gratis melalui situs online, ukuran file yang diciptakan kecil sehingga mempermudah pengoperasian dan penyebaran media, serta memungkinkan perancang media membuat suatu media pembelajaran yang interaktif. Adapun kemampuan program Adobe Flash diungkapkan oleh Asyhar (2012) yaitu dapat membuat animasi, simulasi, dan lainnya. 


\section{METODE PENELITIAN}

Jenis penelitian ini adalah penelitian pengembangan (Research and Development). Penulis memilih kerangka pengembangan ADDIE (Analysis-Design-DevelopmentImplementation-Evaluation).

Dalam penelitian pengembangan ini, subjek uji coba dilakukan pada kelompok kecil yaitu 10 orang siswa kelas XI MAN Model Jambi. Jenis data yang diambil berupa data kualitatif dan data kuantitatif. Instrumen yang digunakan adalah angket validasi ahli materi, angket validasi ahli media, angket penilaian guru dan angket respon siswa. Angket validasi ahli materi dan angket validasi ahli media dianalisis menggunakan teknik analisis data kualitatif dan kuantitatif. Untuk data kuantitatif, penentuan klasifikasi validasi ahli materi dan ahli media didasarkan pada jumlah skor jawaban. Data dianalisis dan diolah menjadi data interval menggunakan skala Likert. Angket penilaian guru dan angket respon siswa dianalisis menggunakan teknik analisis data kualitatif dan kuantitatif berupa persentase kelayakan.

$$
\text { Jarak interval }(i)=\frac{\text { Skor tertinggi }- \text { Skor terendah }}{\text { Jumlah kelas interval }}
$$

Menurut Widoyoko (2012), skala lima memiliki variabilitas lebih tinggi, baik atau lebih lengkap dibandingkan skala empat. Adapun kriteria skala lima yang digunakan yaitu:

$\begin{array}{ll}\text { Sangat Baik } & :(\mathrm{SB}) \\ \text { Baik } & :(\mathrm{B}) \\ \text { Kurang Baik } & :(\mathrm{KB}) \\ \text { Tidak Baik } & :(\mathrm{TB}) \\ \text { Sangat Tidak Baik } & :(\mathrm{STB}) \\ \mathrm{K}=\frac{\mathrm{F}}{\mathrm{N} \times \mathrm{I} \times \mathrm{R}} \times 100 \% & \end{array}$

Keterangan:

$\mathrm{K}=$ Persentase kelayakan

$\mathrm{F} \quad=$ Jumlah keseluruhan jawaban responden

$\mathrm{N}=$ Skor tertinggi dalam angket

I = Jumlah pertanyaan dalam angket

$\mathrm{R}=$ Jumlah responden

Tabel 1 Skala Penilaian Kualifikasi Produk

\begin{tabular}{|c|c|c|}
\hline No. & Persentase & Kriteria \\
\hline 1 & $81 \%-100 \%$ & Sangat baik \\
\hline
\end{tabular}

\begin{tabular}{|c|c|c|}
\hline 2 & $61 \%-80 \%$ & Baik \\
\hline 3 & $41 \%-60 \%$ & Kurang baik \\
\hline 4 & $21 \%-40 \%$ & Tidak baik \\
\hline 5 & $0 \%-20 \%$ & Sangat tidak baik \\
\hline
\end{tabular}

\section{HASIL DAN PEMBAHASAN}

\section{a. Validasi ahli media}

Media pembelajaran yang telah selesai dirancang dan dibuat oleh peneliti kemudian dilakukan tahap validasi oleh ahli media yaitu bapak Dr. rer. nat. Muhaimin, S.Pd, M.Si setelah ahli media melihat, menyimak dan mengoperasikan media pembelajaran yang peneliti rancang, selanjutnya ahli media menilai media pembelajaran tersebut dalam bentuk angket. Hasil validasi tersebut berisikan saran dan perbaikan terhadap media yang dikembangkan.

Angket validasi ini menggunakan pernyataan sikap positif dengan penilaian yang diberikan, yaitu penilaian 5 untuk sangat baik/sesuai, penilaian 4 untuk baik/sesuai, penilaian 3 untuk cukup sesuai, penilaian 2 untuk kurang sesuai dan penilaian 1 untuk sangat tidak baik/sesuai. Validasi oleh ahli media dilakukan sebanyak dua kali. Hasil analisis data validasi pertama dapat ditarik kesimpulan bahwa masih ada huruf dan tulisan yang belum baik dan harus diperbaiki agar mudah dipahami oleh mahasiswa. Kemudian susunan (format) tulisan pada tiap halaman media pembelajaran laboratorium virtual diperbaiki lebih jelas lagi agar seimbang dan agar lebih mudah dipahami mahasiswa. Dari validasi pertama media pembelajaran ini yang dibuat oleh peneliti, mendapatkan penilaian 68 yang dikategorikan "sangat baik", terbukti dari hasil angket dengan menggunakan skala Likert media pembelajaran ini layak untuk diujicobakan di lapangan tetapi dengan revisi, sehingga untuk mendapatkan hasil yang lebih maksimal lagi peneliti melakukan revisi berdasarkan saran oleh ahli media. Kemudian dilanjutkan dengan validasi media pembelajaran laboratorium virtual tahap kedua dan diperoleh penilaian lebih tinggi daripada validasi pertama yaitu 71

Berdasarkan skala Likert range nilai 6375 dalam kategori "sangat baik" dan media ini layak diujicobakan tanpa revisi, artinya media 
yang ditampilkan sudah layak untuk diujicobakan di lapangan pada kelompok kecil.

\section{b. Validasi ahli media}

Validasi selanjutnya adalah validasi ahli materi dengan ahli materi yaitu bapak Dra. Wilda Syahri , M.Pd. Hal yang dinilai adalah kesesuain materi dengan penjelasan literatur yang ditampilkan dalam media laboratorium virtual serta kesesuaian materi yang ditampilkan dengan kurikulum. Setelah ahli materi melihat dan menyimak media pembelajaran yang peneliti rancang, selanjutnya ahli materi juga menilai media pembelajaran tersebut menggunakan angket Hasil validasi tersebut didapatkan saran dan perbaikan materi terhadap media yang dikembangkan dan diperoleh data.

Angket validasi ini juga menggunakan pernyataan sikap positif dengan penilaian yang diberikan, yaitu penilaian 5 untuk sangat baik/sesuai, penilaian 4 untuk baik/sesuai, penilaian 3 untuk cukup sesuai, penilaian 2 untuk kurang sesuai dan penilaian 1 untuk sangat tidak baik/sesuai. Validasi oleh ahli media dilakukan sebanyak dua kali.

Berdasarkan penilaian validator didapatkan skor 54 yang dikategorikan "baik" merujuk pada skala Linker. Dari analisis angket validasi media pembelajaran laboratorium virtual laju reaksi ini serta keseluruhannya sudah sesuai dengan tujuan pembelajaran. Namun, masih terdapat beberapa hal yang harus diperbaiki oleh peneliti seperti menambahkan contoh penerapan laju reaksi pada kehidupan sehari-hari untuk tiap materinya, ukuran huruf pada materi disesuaikan dan menambahkan judul materinya pada halaman awal literatur serta validator juga menyarankan agar soal latihan pada materi dibuat lebih bervariasi tetapi harus sesuai dengan indikator yang digunakan. Setelah validasi materi tahap pertama selesai, kemudian dilanjutkan dengan validasi materi tahap kedua dan diperoleh penilain lebih tinggi daripada validasi pertama yaitu 71 .

Berdasarkan jumlah penilaian maka jumlah penilaian yang didapatkan peneliti atas materi yang ditampilkan dalam media pembelajaran ini 71 yang dikategorikan "sangat baik" merujuk kepada skala Linker, dari hasil validasi tersebut, materi yang ditampilkan layak untuk diujicobakan pada kelompok kecil.

\section{c. Tanggapan mahasiswa dan penilaian dosen}

Media yang telah selesai divalidasi oleh tim ahli, selanjutnya dinilai oleh dosen sebagai pengguna, sebelum nantinya diujicobakan ke mahasiswa. Penilaian dari dosen ini nantinya digunakan sebagai tambahan perbaikan terhadap media yang dikembangkan dan apakah cocok digunakan sebagai sumber belajar. Hal tersebut didukung oleh Asyhar (2012) bahwa media yang baik memiliki fungsi sebagai sumber belajar yaitu sebagai penyalur, penyampai dan penghubung pesan/pengetahuan dari pebelajar kepada pembelajar.

Hasil yang diperoleh dari penilaian dosen tersebut mengenai media pembelajaran laboratorium virtual laju reaksi diperoleh jumlah penilaian dari hasil penilaian dosen yaitu 72 dengan kategori "sangat baik" merujuk kepada skala Linker. Sehingga produk yang dikembangkan layak digunakan sebagai salah satu sumber belajar kimia dan layak untuk diujicobakan ke kelompok kecil.

Setelah mahasiswa menggunakan media laboratorium virtual, kepada mahasiswa dibagikan angket untuk melihat respon mahasiswa. Dari angket diperoleh 88,29 \% mahasiswa menyatakan media ini layak digunakan. Sebanyak $95 \%$ mahasiswa menyaakan mudah menggunakanya, $100 \%$ menyatakan setuju media ini digunakan untuk pembeljaran dan $100 \%$ menyatakan lebih paham mempelajari laju reaksi melalui laboratorium virtual yang dikembangkan.

Hasil pernyataan tersebut didukung oleh pendapat Asyhar (2012:29) bahwa media memiliki fungsi psikologis yakni fungsi yang berkaitan dengan aspek psikologis yang mencakup fungsi atensi (menarik perhatian) dan fungsi motivasi (mendorong dan membangkitkan minat belajar). Sedangkan pada pernyataan kelima yang menyatakan gambar dan animasi praktikum yang ditampilkan memudahkan mahasiswa dalam memahami konsep-konsep laju reaksi diperoleh nilai 45 . Hal tersebut sesuai dengan pendapat Donlley dalam (Sutrisno, 2011) dengan melakukan praktikum akan memberikan pemahaman 
kepada mahasiswa dalam ilmu kimia kearah realitas dan menarik serta memahami konsepkonsep yang bersifat abstrak menjadi lebih mudah dipahami.

\section{d. Hasil Pengembangan}

Hasil akhir dari penelitian

pengembangan media laboratorium virtual ini diantaranya:

1. Sebuah media pembelajaran berupa laboratorium virtual untuk materi laju reaksi dengan menggunakan software adobe flash.

2. Penilaian produk media pembelajaran laboratorium virtual untuk materi laju reaksi menggunakan software adobe flash oleh ahli materi dan ahli media.

3. Tanggapan dan penilaian dosen terhadap media laboratorium virtual yang telah dibuat dengan memberikan angket penilaian dosen.

4. Respon mahasiswa terhadap media laboratorium virtual yang telah dibuat dengan menyebarkan angket kepada 10 mahasiswa Pendidikan Kimia.

Pada pengembangan media pembelajaran laboratorium virtual ini, peneliti menggunakan model ADDIE dimana model ini terdiri atas 5 tahap, yaitu: Analisis, Desain, Development, Implementasi dan Evaluasi. Dari analisis kebutuhan, karakteristik mahasiswa, tujuan dan materi diperoleh bahwa media lab virtual untuk materi laju reaksi perlu dikembangkan.

Desain media pembelajaran laboratorium virtual pada tahap pertama adalah membuat flowchart, yang akan digunakan pada proses produksi. Selanjutnya berdasarkan flowchart tersebut kemudian dilakukan pengumpulan gambar-gambar dari internet, membuat teks yang akan diconvert ke media, menetapkan animasi praktikum yang sesuai dengan materi, mengumpulkan musik-musik instrument sebagai musik pengiring dan buku untuk mendukung materi yang akan dibutuhkan dalam pembuatan media laboratorium virtual. Berikut hasil flowchart atau diagram alur media pembelajaran laboratorium virtual untuk materi laju reaksi menggunakan software adobe flash:

Tahap pengembangan adalah proses mewujudkan storyboard yang telah dibuat sebelumnya menjadi dasar dalam pengembangan media. Produk yang dihasilkan yaitu media pembelajaran laboratorium virtual menggunakan software adobe flash. Pada pengembangan media ini melalui beberapa tahap yaitu (1) mengumpulkan bahan materi yang akan dimasukkan ke dalam media laboratorium virtual; (2) membuat gambar dan animasi praktikum faktor-faktor yang mempengaruhi laju reaksi; (3) menggabungkan dan menyusun teks, gambar, audio serta latihan agar sesuai dengan media laboratorium virtual; (4) validasi media laboratorium virtual oleh tim ahli (ahli media dan ahli materi); (5) revisi oleh tim ahli; (6) penilaian oleh dosen dan (7) ujicoba kelompok kecil, berikut desain produk media pembelajaran laboratorium virtual untuk materi laju reaksi:

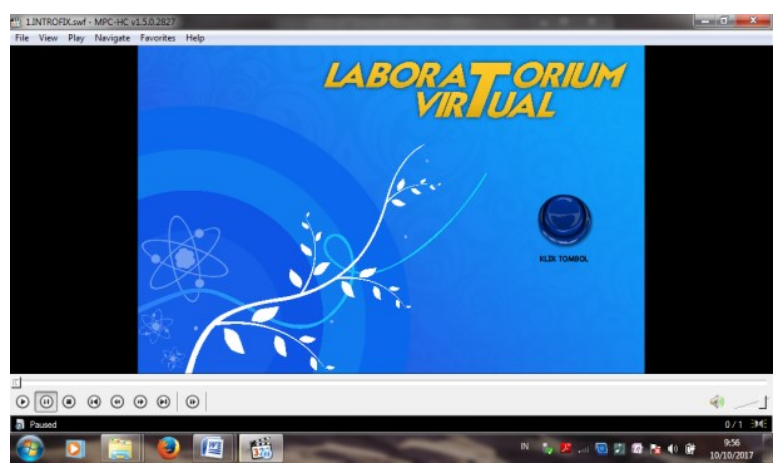

Gambar 5.4 Halaman pembuka media laboratorium virtual

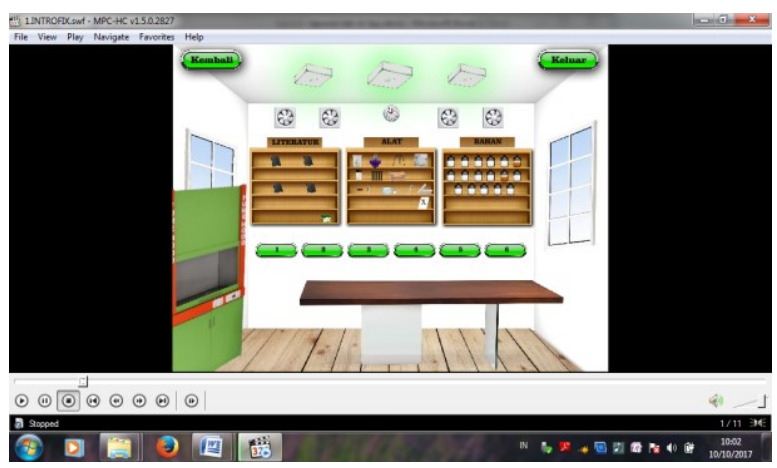

Gambar 5.5 Halaman ruangan laboratorium virtual 


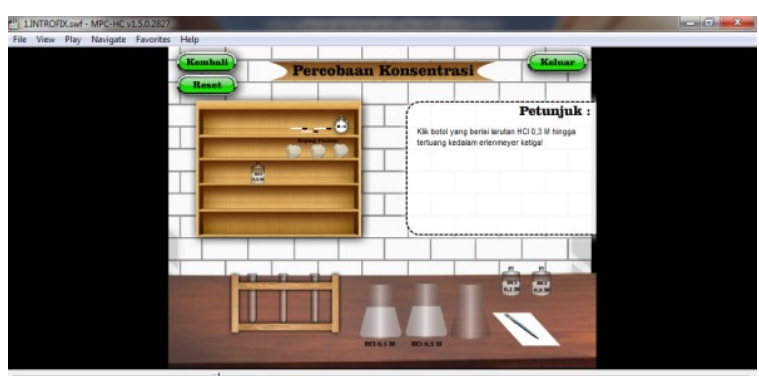

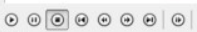

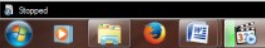

Gambar 5.6 Halaman percobaan pengaruh konsentrasi terhadap laju reaksi

\section{SIMPULAN}

Berdasarkan hasil penelitian dan pembahasan tentang pengembangan laboratorium virtual materi laju reaksi dengan menggunakan software adobe flash, dapat ditarik kesimpulan sebagai berikut:

1. Produk yang dihasilkan media pembelajaran laboratorium virtual menggunakan software adobe flash, yang dikembangkan dengan model pengembangan ADDIE untuk materi laju reaksi dinyatakan layak untuk digunakan menurut validator media dan materi.

2. Setelah diminta respon dosen kimia dasar, dosen kimia dasar menyatakan media pembelajaran laboratorium virtual menggunakan software adobe flash untuk materi laju reaksi layak digunakan.

3. Respon mahasiswa terhadap media pembelajaran laboratorium virtual menggunakan software adobe flash untuk materi laju reaksi juga sangat baik.

\section{REFERENSI}

Asyhar, R., 2012. Kreatif Mengembangkan Media Pembelajaran. Jakarta: GP Press.

Epinur dan Yusnidar, 2016, Pengembangan Laboratorium Virtual Dengan Macromedia Flash 8 Materi Larutan Asam-Basa Untuk Kimia Dasar II Prodi Pendidikan Kimia, Laporan Penelitian, Universitas Jambi.

Madcoms, 2011. Adobe flash cs6 Professional. Yogyakarta: C.V Andi OFFSET.

Mulyatiningsih. 2011. Konstruksi Pengembangan Pembelajaran. Jakarta:

Prestasi Pustaka.
Mustaji, 2009. Pemanfaatan Laboratorium dalam Pembelajaran dengan Pendekatan Sains. Jakarta : UNIMAL Press.

Pribadi, B.A., 2009. Model Desain Sistem Pembelajaran. Jakarta: Dian Rakyat.

Pujiati, A., dan Nurhayati. (2014). Pengaruh Model Pembelajaran (Berbantuan Labboratorium Virtual) dan Minat Belajar Terhadap Kemampuan Berpikir Kreatif Kimia. Jakarta: Universitas Indraprasta. Diakses tanggal 16 Desember 2014

Razi, P. (2013). Hubungan Motivasi Dengan Kerja Ilmiah Siswa Dalam Pembelajaran Fisika Menggunakan Virtual Laboratory Di Kelas X SMAN Kota Padang. Padang: UNP. Diakses tanggal 16 Desember 2014

Sugiyono, 2014. Metode Penelitian Pendidikan. Bandung: Alfabeta.

Sutarno (2013). Pengaruh Penerapan Model Praktikum Virtual Berbasis Problem Solving Terhadap Kemamuan Kemampuan Berpikir Kritis Mahasiswa. Universitas Bengkulu. Diakses tanggal 15 Desember 2014.

Sutrisno, 2011. Pengantar Pembelajaran Inovatif. Jakarta: GP Press. , 2012. Kreatif Mengembangkan Aktivitas Pembelajaran Berbasis TIK. Jakarta: GP Press.

Tatli, Z., dan Ayas, A. (2013). Effect of a Virtual Chemistry Laboratory on Students' Achievement. Educational Technology \& Society, 16 (1), 159-170. Diakses tanggal 15 Desember 2014.

Walgito, B., 2010. Pengantar Psikologi Umum. Yogyakarta : CV.Andy Offeset. 